\title{
Pyrolysis of petroleum asphaltenes from different geological origins and use of methylnaphthalenes and methylphenanthrenes as maturity indicators for asphaltenes
}

\author{
MANOJ KUMAR SARMAH*, ARUN BORTHAKUR ${ }^{\dagger}$ and ARADHANA DUTTA \\ Oil India Limited, P.O. Duliajan, Dist. Dibrugarh 786 602, India \\ ${ }^{\dagger}$ North East Institute of Science and Technology, P.O. Jorhat 786 001, India \\ ${ }^{\ddagger}$ Dibrugarh University, P.O. Dibrugarh 786 002, India
}

MS received 10 February 2009; revised 7 September 2012

\begin{abstract}
Asphaltenes separated from two different crude oils from upper Assam, India, having different geological origins, viz. DK (eocene) and JN (oligocene-miocene) were pyrolysed at $600{ }^{\circ} \mathrm{C}$ and the products were analysed by gas chromatography-mass spectrometry (GC/MS) especially for the generated alkylnaphthalenes and alkylphenanthrenes. Both the asphaltenes produce aliphatic as well as aromatic compound classes. Alkylnaphthalenes and alkylphenanthrenes were identified by using reference chromatograms and literature data and the distributions used to assess thermal maturity of the asphaltenes. The ratios of $\beta$-substituted to $\alpha$-substituted isomers of both alkylnaphthalenes and alkylphenanthrenes revealed higher maturity of the JN asphaltenes than the DK asphaltenes. For both the asphaltenes, the abundance of 1-methylphenanthrene dominates over that of 9-methylphenanthrene showing the terrestrial nature of the organic matter.
\end{abstract}

Keywords. Maturity; methylnaphthalenes; methylphenanthrenes; asphaltenes; pyrolysate; kerogen.

\section{Introduction}

The complexity of petroleum fractions increases with increase in boiling point owing to the exponential increase in the number of isomers for a given carbon number. Moreover, the presence of aromatic and heteroatom-containing compounds makes it very difficult to study the detailed composition of the heavier ends of petroleum. However, the rapid depletion in oil resources forces us to study and utilize every fraction throughout the refining processes (Neurock and Klein 1995). The heavy ends of petroleum, especially, asphaltenes represent an enigmatic yet important class of compounds (Bunger and $\mathrm{Li}$ 1984; Sheu and Mullins 1995; Mullins and Sheu 1998). They strongly influence the rheology of paving material (Sheu and Mullins 1995; Mullins and Sheu 1998) and impact on the production, transportation and refining of crude oils (Bunger and Li 1984; Sheu and Mullins 1995; Mullins and Sheu 1998). Asphaltenes are brown to black amorphous solids containing carbon, hydrogen, nitrogen, oxygen and sulphur. They are believed to be made up of condensed aromatic rings with short aliphatic chains and naphthenic ring structures, as well as being of high molecular weight (Nali et al 1995). The classical definition of asphaltenes is based on the solu-

\footnotetext{
*Author for correspondence (manoj_sarmah@oilindia.in)
}

tion properties. They are defined as the $n$-pentane insoluble and benzene soluble fractions of coal or petroleum. Later it was demonstrated that the elemental composition of asphaltene fractions precipitated by different solvents from various sources of petroleum varies considerably (Kawanalca $e t$ al 1989). Several authors considered them as the most labile part of the respective kerogen in oil reservoirs (Speight and Moschopedis 1981; Arefyev et al 1982). So, the study of asphaltenes brings important clues concerning the chemical reactions taking place during kerogen maturation. Pyrolysis (Py) followed by (GC/MS) has provided new insight into their structure, especially for side chains on polyaromatic nuclei. Several reaction pathways have been proposed for asphaltene pyrolysis (Rubinstein and Strausz 1979; Larter and Douglas 1982; Neurock et al 1990; Murata et al 1995; Yasar et al 2001). For example, the pyrolysis at $350-800^{\circ} \mathrm{C}$ produces substantial amount of alkanes and polynuclear aromatic hydrocarbons. Py-GC has become a tool for correlation studies. Rubinstein and Strausz (1979) tried to correlate biodegraded oil with its "normal" oil. The study of asphaltenes is also important as there exist striking physical and chemical similarities between oil-forming kerogen and petroleum asphaltenes which in turn may provide better understanding of their role in petroleum generation, migration and maturation. Asphaltenes are emerging as frontier molecules in geochemical research as they provide important clues about nature and source of organics, maturation, migration and secondary alteration effects. They represent a major class of 
petroleum components that have no analogous counterpart in the biological systems. This suggests that they are secondary products formed after the deposition of the source material. They may be fragments of the original kerogen from which the petroleum is derived and may be expelled as part of it. In addition to their geological significance, they are indispensable in either demonstrated or proven applications in production and refining (International conference on petroleum geochemistry and exploration in Afro-Asian region, Nov 1985). The alkylnaphthalenes and alkylphenanthrenes have widely been used as thermal maturation indicators (Radke 1987; Stojanovic et al 2001; Shuichang et al 2005; Asif and Tahira 2007). In the present communication, asphaltenes from two crude oils of different sources were pyrolysed at $600^{\circ} \mathrm{C}$ in a pyrolyser and the different alkylnaphthalenes and alkylphenanthrenes generated in the pyrolysates were used to assess the maturities of the two asphaltenes.

\section{Experimental}

Asphaltenes (ca. $2 \mathrm{mg}$ ) separated from the $300^{\circ} \mathrm{C}+$ fraction of DK and JN were introduced into a PY-2020iD doubleshot pyrolyzer at $600{ }^{\circ} \mathrm{C}$, which was directly connected to a GC/MS instrument comprising a thermo trace gas chromatograph and a thermo DSQ mass spectrometer. The GC column was DB-1 (30 $\mathrm{m} \times 0.35 \mathrm{~mm}$ i.d., $0.32 \mu \mathrm{m}$ film thickness) and the oven temperature programme was $-35^{\circ} \mathrm{C}(5 \mathrm{~min})$ to $300{ }^{\circ} \mathrm{C}$ at $2{ }^{\circ} \mathrm{C} / \mathrm{min}$ (holding time, $5 \mathrm{~min}$ ). The chromatograph conditions were: split injector $300^{\circ} \mathrm{C}$; split flow $20 \mathrm{ml} / \mathrm{min}$; split ratio 20:1; carrier gas He at constant flow; transfer line $300^{\circ} \mathrm{C}$. The MS operating conditions were: ion source $200^{\circ} \mathrm{C}$, full scan with mass range $50-500 \mathrm{amu}$, total time of analysis $105 \mathrm{~min}$.

\section{Results and discussion}

The physical characteristics of the two crude oils, DK and $\mathrm{JN}$, are presented in table 1. They were selected on the basis of their geological time scale. DK is from eocene and JN from oligocene-miocene origin. The distillation characteristics are presented in table 1 . Petroleum asphaltenes have been a subject of pyrolytic studies for more than a decade (e.g. Moschopedies et al 1978; Gonzalez et al 2001); it provides an important quantitative information on identity, composition and structure. Here, the asphaltenes were pyrolysed at $600^{\circ} \mathrm{C}$ and the products were analysed using GC/MS. Figures 1 and 2 show partial mass chromatograms for the methylnaphthalenes and methylphenanthrenes in the pyrolysates of JN and DK asphaltenes, respectively. A general feature is, apart from the presence of a series of $n$-alkane/ $n$-alkene doublets the abundance of aromatic biological markers such as alkylnaphthalenes and alkylphenanthrenes were identified through MS library, Wiley and comparison with other published data. Alkylnaphthalenes
Table 1. Physical characteristics of crude oil.

\begin{tabular}{lcc}
\hline & \multicolumn{2}{c}{ Oil } \\
\cline { 2 - 3 } Physical properties & DK & JN \\
\hline Origin & Eocene & Oligocene-miocene \\
Density & $0 \cdot 8843$ & $0 \cdot 856$ \\
API gravity & $28 \cdot 6$ & $33 \cdot 7$ \\
Pour point $\left({ }^{\circ} \mathrm{C}\right)$ & 30 & 24 \\
Dist. characteristics IBP\% & 78 & 85 \\
Vol.\% at $\left({ }^{\circ} \mathrm{C}\right)$ & & \\
5 & 142 & 85 \\
10 & 170 & 122 \\
15 & 202 & 140 \\
20 & 240 & 164 \\
25 & 258 & 206 \\
30 & 280 & 236 \\
33 & 300 & 268 \\
35 & & 294 \\
40 & & 300 \\
42 & & \\
\hline
\end{tabular}

and alkylphenanthrenes were the most abundant compound classes which are discussed in detail. The identified ones and their abundance in the pyrolysates are presented in table 2.

\subsection{Origin and geochemical significance of alkylnaphthalenes}

Alkylnaphthalenes are mainly derived from terrestrial sources (Radke and Willsch 1994) and several precursors are known: cyclic sesquiterpenoids derived from resinous constituents of conifers are potential precursors of alkylnaphthalenes (Pentegova et al 1968); thermal degradation of $\beta$-carotene led to the formation of 2,6-dimethylnaphthalene, 1- and 2-methylnaphthalene and naphthalene (Day and Erdman 1963; Achari et al 1993), 1,2,7-trimethylnaphthalene is suggested to originate from compounds like $\beta$-amyrin that are constituents of angiosperms (Strachan et al 1988); $\beta$-amyrin and monoaromatic seco-hopanes are among several potential precursors of 1,2,5-trimethylnaphthalene and 1,2,5,6-tetramethylnaphthalene (Püttmann and Villar 1987); 1,2,4-trimethylnaphthalene might originate from $\alpha$ tocopherol present in recent marine sediments (Brassell et al 1985); 1,2,2',5-tetramethyltetralin and 1,2,2',5,6pentamethyltetralin from microbial sources, might be precursors of 1,2,6-trimethylnaphthalene, 1,2,5,7- and 1,2,3, 5-tetramethylnaphthalene (Alexander et al 1992).

Some alkylnaphthalenes have various potential biological sources. Strachan et al (1988) found high proportions of 1,2,5- and 1,2,7-trimethylnaphthalene in sediments of cretaceous age and younger. The degradation of $\beta$-amyrin via 8,14-seco-triterpenoids is supposed to additionally yield in high proportions of 1,2,5,6-tetramethylnaphthalene 


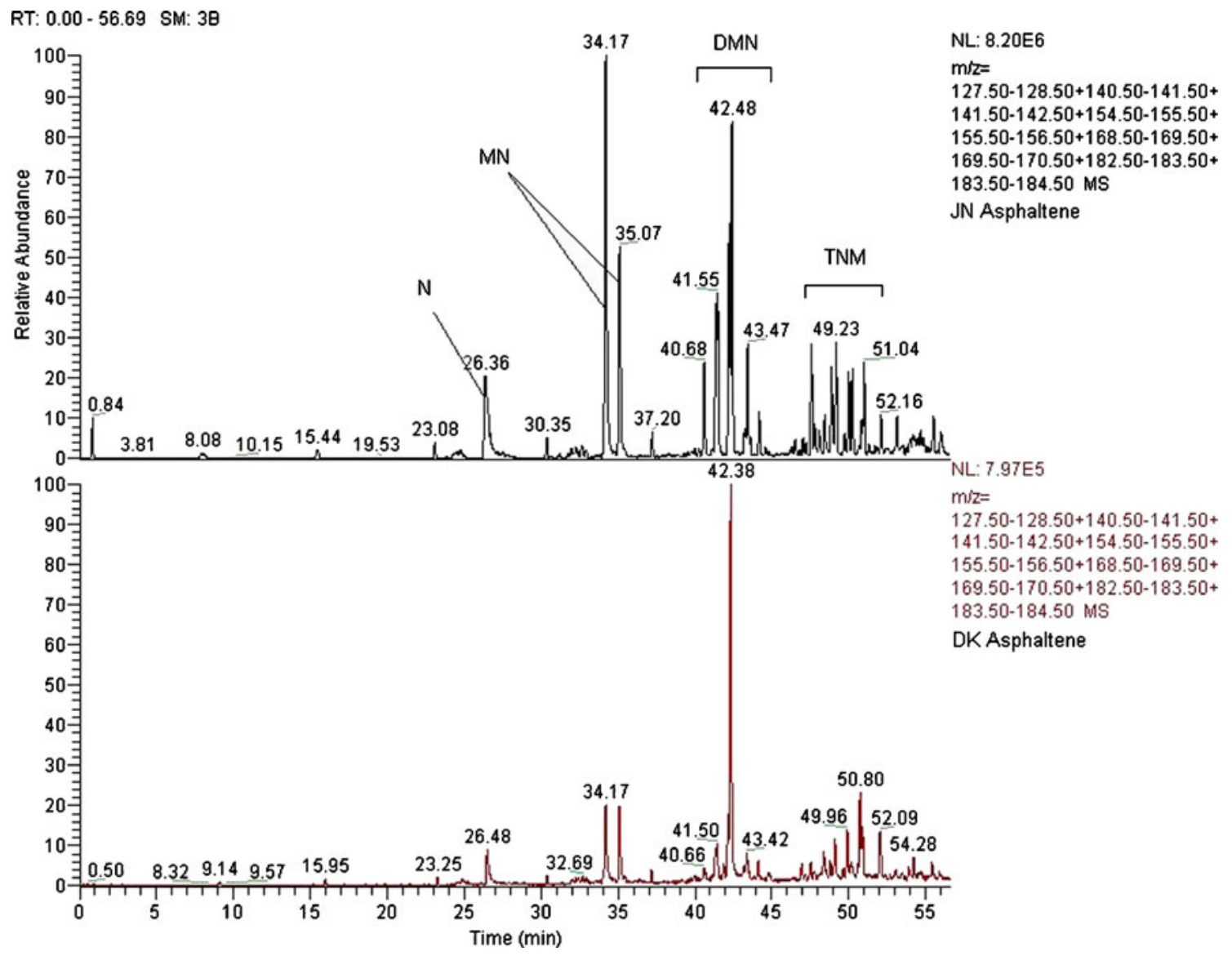

Figure 1. Partial summed mass chromatograms for alkylnaphthalenes in DK and JN asphaltene pyrolysates $(\mathrm{N}=$ naphthalene; $\mathrm{MN}=$ methylnaphthalene and $\mathrm{DMN}=$ dimethylnaphthalene).

(Püttmann and Villar 1987). High proportions of 1,2,7trimethylnaphthalene have been attributed to the contribution of angiosperms to sediments. In contrast, 1,2,5trimethyl- and 1,2,5,6-tetramethyl naphthalene may also derive from other natural precursors. They may be formed via degradation of monoaromatics seco-hopanoids (Hussler et al 1984). Additionally, both 1,2,5-trimethyl- and 1,2,5,6tetramethyl naphthalene were detected as major constituents in the fluorinate filling of needles from Abietites linkii, a gymnosperm (Heppenheimer et al 1992); 1,2, 5-trimethylnaphthalene may also originate from the dehydrogenation of biological precursors like agathic acid, communic acid and manool (Thomas 1970; Carman and Craig 1971). The latter compounds are constituents of gymnosperms (Karrer 1976; Thomas 1970).

To recognize source effects, Strachan et al (1988) compared the relative amounts of 1,2,7- to 1,3,7-trimethylnaphthalene and those of 1,2,5- to 1,3,6-trimethylnaphthalene. While 1,2,7- and 1,2,5-trimethylnaphthalene are supposed to have direct biogenic precursors, 1,3,7- and 1,3,6trimethylnaphthalene are suggested to originate from the isomerization of these two potential biomarkers. Although the two ratios depend on the maturity of the samples, source effects are assumed to be recognizable from establishing a logarithmic plot (Strachan et al 1988).

\subsection{Origin and geochemical significance of alkylphenanthrenes}

Diterpenoids, with an abietane and pimarane skeleton are likely biological precursors of alkylphenanthrenes (Simoneit et al 1986). These compounds are constituents of ambers and resins (Thomas 1970; Simoneit et al 1986) in vascular plants. The most prominent alkylphenanthrene, directly attributed to diterpenoids of the abietane type is 1-methyl-7isopropylphenanthrene (retene). 1,7-dimethylphenanthrene (premanthrene) probably originates from diterpenoids of the premarane type but is also a potential decomposition product of retene (Simoneit et al 1986). Additionally, phenanthrene and alkylphenanthrenes may originate from pentacyclic triterpenoids or steroids (Streibl and Herout 1969; Greiner et al 1976). A detailed study of the distribution of alkylphenanthrenes regarding their potential biological origin and dependence on maturity has been carried out by Budzinski et al (1995). The authors compared the distributions of methyl, dimethyl and trimethylphenanthrenes in samples originating from terrestrial and marine sources. High proportions of 1-methylphenanthrene were preferentially found in the organic matter of terrestrial source rocks, whereas 9-methylphenanthrene was relatively enriched in organic matter from marine shales. Additionally, a 


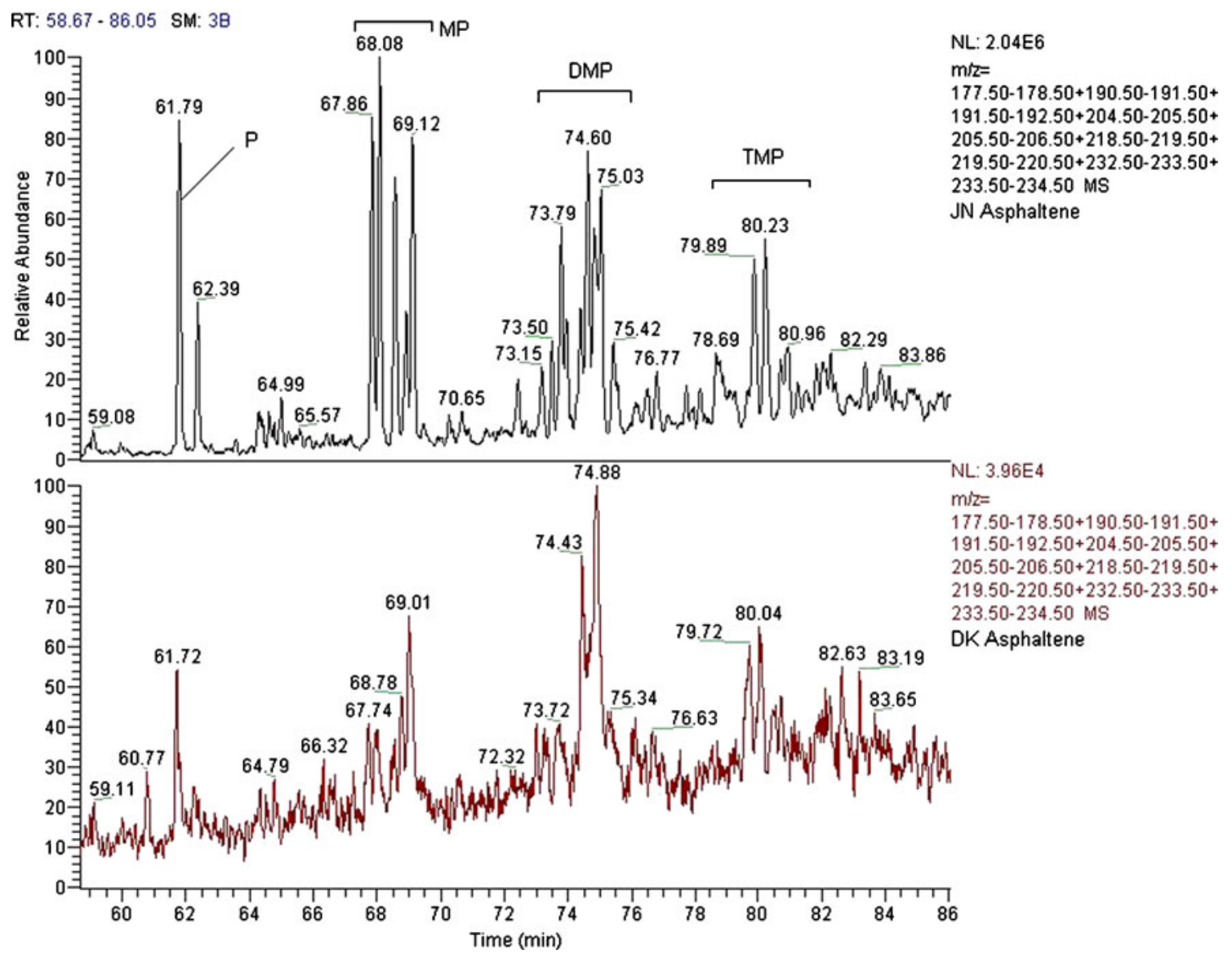

Figure 2. Partial summed mass chromatograms of alkylphenanthrenes in DK and JN asphaltene pyrolysates $(P=$ phenantherene; $\mathrm{MP}=$ methylphenanthrene; $\mathrm{DMP}=$ dimethylphenanthrene and $\mathrm{TMP}=$ trimethylphenanthrene).

predominance of pimanthrene and retene has been attributed to terrestrial organic matter. Among trimethylphenanthrenes, $1,2,8$-isomer, was in general the most abundant isomer. While there is so much evidence for the biological origin of alkylnaphthalenes, investigation of them mainly addresses their common use as maturity parameters (Radke et al 1982b). In immature samples, 9-methylpenanthrene and 1-methylphenanthrene are often highly abundant, with 9-methylphenanthrene being predominant (Radke et al 1982a). With increasing maturity, 2-methylphenanthrene and 3-methylphenanthrene become more prominent, due to their enhanced thermal stability. Normally, 2-methylphenanthrene is present in higher proportions than 3-methylphenanthrene (Alexander et al 1992). Based on these observations, the methylphenanthrene ratio (MPI 1, table 3) was established, showing an excellent correlation with the vitrinite reflectance for organic material of type III kerogen (Radke et al 1982a). Therefore, the vitrinite reflectance $\left(R_{r}\right)$ of terrestrial organic matter, with ratios of MPI1 ratio $<2.65$ can be approximated by calculation $\left(R_{r}\right.$, table 3$)$. MPI 2 normally is little enhanced in comparison to MPI 1 , due to the slight predominance of 2-methylphenanthrene.

The maturity of the asphaltenes was determined on the basis of maturity ratios of alkylnaphthalenes and alkylphenanthrenes (table 3). Several ratios based on the distribution of alkylnaphthalenes therefore compare the amounts of more stable to less stable isomers. The more stable isomers are substituted at positions 2, 3, 6 and 7 of the naphthalene skeleton. Radke et al (1982b) found that samples of enhanced $\left(>0.9 \% R_{r}\right)$ show elevated proportions of 2-methylphenanthrene vs 1-methylphenanthrene. This also accounts for the ratio of 2-methylphenanthrene to 1-methylphenanthrene (table 3). Instead of peak areas, peak heights of the compounds were taken for calculation of maturity ratios due to the poor resolution of some peaks. The relative abundances are presented in table 2. The naphthalene concentration in DK-asphaltene pyrolysates is much higher than $\mathrm{JN}$-asphaltene pyrolysates. MNR increases with increasing maturity. It reveals from table 3 that MNR for $\mathrm{JN}$ is almost double that for DK, i.e. the more stable $\beta$ isomer (2-methylnaphthalene) predominates over less stable $\alpha$-isomer (1-methylnaphthalene) in JN. For DK, both isomers have equal concentrations. Like MNR, the ratios of dimethylnaphthalenes (DNR) and trimethylnaphthalenes (TNR 1 and TNR 2) also increase with increasing maturity (table 3). Amongst dimethylnaphthalenes, 1,6-DMN has the highest and 1,5-DMN has the lowest concentration for DK whereas in JN the highest concentration was observed for 1,2-DMN and the lowest for 1,4-DMN+2,3-DMN. Both 1,4-DMN and 2,3-DMN elute at the same retention time 
and appears as a single peak. The DNR ratio for DK is 1.77 and for JN 2.79. This means that the more stable $\beta, \beta^{\prime}$ isomers (2,6- and 2,7-dimethylnaphthalenes) predominate

Table 2. Relative abundance of alkylnaphthalenes and alkylphenanthrenes of DK- and JN-asphaltenes pyrolysates.

\begin{tabular}{|c|c|c|}
\hline \multirow[b]{2}{*}{ Compounds } & \multicolumn{2}{|c|}{ Abundance $\%$} \\
\hline & DK & $\mathrm{JN}$ \\
\hline Naphthalene & 3.67 & 0.01 \\
\hline 2-methylnaphthalene & $0 \cdot 29$ & 0.97 \\
\hline 1-methylnaphthalene & $0 \cdot 30$ & 0.53 \\
\hline 2,6-dimethylnaphthalene & 0.09 & $0 \cdot 35$ \\
\hline 2,7-dimethylnaphthalene & $0 \cdot 10$ & $0 \cdot 38$ \\
\hline 1,3-DMN+1,7-DMN & 0.29 & 0.58 \\
\hline 1,6-DMN & $1 \cdot 33$ & $0 \cdot 80$ \\
\hline 1,4-DMN+2,3-DMN & $1 \cdot 16$ & $0 \cdot 06$ \\
\hline 1,2-DMN & $0 \cdot 64$ & 0.97 \\
\hline 1,5-DMN & 0.05 & $0 \cdot 14$ \\
\hline 1,3,7-TMN & $0 \cdot 10$ & $0 \cdot 24$ \\
\hline $1,3,6-\mathrm{TMN}$ & $0 \cdot 25$ & 0.76 \\
\hline 1,3,5-TMN+1,4,6-TMN & $0 \cdot 16$ & $0 \cdot 20$ \\
\hline 2,3,6-TMN & 0.03 & $0 \cdot 21$ \\
\hline $1,2,7-\mathrm{TMN}$ & $0 \cdot 10$ & 0.03 \\
\hline 1,6,7-TMN & $0 \cdot 28$ & $0 \cdot 12$ \\
\hline 1,2,6-TMN & $0 \cdot 15$ & $0 \cdot 22$ \\
\hline $1,2,4-\mathrm{TMN}$ & 0 & 0.03 \\
\hline $1,2,5-\mathrm{TMN}$ & $0 \cdot 15$ & 0.09 \\
\hline Phenanthrene & $0 \cdot 06$ & $0 \cdot 28$ \\
\hline $3 \mathrm{MP}$ & $0 \cdot 06$ & $0 \cdot 25$ \\
\hline 2MP & $0 \cdot 04$ & $0 \cdot 27$ \\
\hline 9MP & $0 \cdot 05$ & $0 \cdot 15$ \\
\hline $1 \mathrm{MP}$ & $0 \cdot 15$ & $0 \cdot 22$ \\
\hline
\end{tabular}

$\mathrm{MN}=$ methylnaphthalene; $\mathrm{DMN}=$ dimethylnaphthalene; $\mathrm{TMN}=$ trimethylnaphthalene and MP = methylphenanthrene. more over the $\alpha, \alpha$-isomer (1,5-dimethylnaphthalene) for JN than DK. The distribution of alkylnaphthalenes is supposed to be mainly influenced by the thermal history. Increasing maturity results, for example, in the progressive conversion of 1,2,5-trimethylnaphthalene to the 1,3,6-trimethylnaphthalene and other isomers (Strachan et al 1988). This results from isomerization reactions, leading to the predominance of more stable isomers with increasing maturity. The TNNr and TrMN ratios reveal that the conversion of 1,2,5-trimethylnaphthalene to the more stable 1,3,6-trimethylnaphthalene appears to be greater for JN asphaltenes than DK asphaltenes. Amongst the trimethylnaphthalenes, the 1,3,6- and 1,6,7-isomers are present in significant quantities for DK whereas for JN, the 1,2,6-, 2,3,6-, 1,3,5 + 1,4,6- and, in particular, 1,3,6-trimethylnaphthalenes are present in significant quantity. TNR 1 and TNR 2 for DK and JN are $0.1,1.05$ and $0.32,0.47$, respectively. The comparison of all the methylnaphthalene ratios indicates that all the ratio values are greater for JN than DK asphaltenes pyrolysates (figures 3 and 4 ). This proves that $\mathrm{JN}$ is more mature than DK.

Different ratios of methylphenanthrenes have been used by petroleum geochemists as thermal maturity indices (Radke et al 1986). The maturity of DK and JN asphaltenes was assessed by applying these ratios. Alkylphenanthrenes are the common constituents of sedimentary organic matter. They have been reported in shales (Radke et al 1982a; Fisher et al 1996; Borrego et al 1997), coal and crude oil (Fisher et al 1996; Borrego et al 1997). Methylphenanthrenes were commonly observed for both asphaltenes. 2-methylphenanthrene and 3-methylphenanthrene being present to some extent in higher concentration than 1-methylphenanthrene and 9methylphenanthrene for JN asphaltene. For DK asphaltene, the concentration of 1-methylphenanthrene was highest followed by 2-methylphenanthrene, 3-methylphenanthrene

Table 3. Methylnaphthalene and methylphenanthrene ratios for DK and JN asphaltenes.

\begin{tabular}{|c|c|c|c|c|}
\hline Name & Maturity ratio & Ref. & DK & $\mathrm{JN}$ \\
\hline MNR & $2 \mathrm{MN} / 1 \mathrm{MN}$ & Radke et al (1982b) & 0.97 & 1.83 \\
\hline DNR & 2,6+2,7-DMN/1,5-DMN & Radke et al (1982b) & $3 \cdot 80$ & $5 \cdot 21$ \\
\hline TNR 1 & 2,3,6-TMN/1,3,5+1,4,6-TMN & Alexander et al (1985) & $0 \cdot 19$ & 1.05 \\
\hline TNR 2 & $1,3,7+2,3,6-\mathrm{TMN} / 1,3,5+1,3,6+1,4,6-\mathrm{TMN}$ & Radke et al (1986) & $0 \cdot 32$ & 0.47 \\
\hline $\mathrm{TNNr}$ & $1,3,7-\mathrm{TMN} / 1,3,7+1,2,5-\mathrm{TMN}$ & van Aarssen et al (2000) & $0 \cdot 40$ & 0.73 \\
\hline TrMN & $1,3,7+1,3,6+2,3,6-\mathrm{TMN} / \sum \mathrm{TMN}$ & Kruge (2000) & $0 \cdot 31$ & $0 \cdot 64$ \\
\hline MPI 1 & $1.5(2 \mathrm{MP}+3 \mathrm{MP}) / \mathrm{P}+1 \mathrm{MP}+9 \mathrm{MP}$ & Radke et al (1982a) & $0 \cdot 58$ & $1 \cdot 2$ \\
\hline MPI 2 & $3(2-\mathrm{MP}) / \mathrm{P}+1-\mathrm{MP}+9-\mathrm{MP}$ & Radke et al (1982a) & 0.46 & $1 \cdot 25$ \\
\hline MPI 3 & $(2 \mathrm{MP}+3 \mathrm{MP}) /(1 \mathrm{MP}+9 \mathrm{MP})$ & Radke et al (1987) & $0 \cdot 5$ & $1 \cdot 4$ \\
\hline MPR & 2-MP/1-MP & Radke et al (1982b) & $0 \cdot 27$ & $1 \cdot 23$ \\
\hline $\mathrm{Rc}$ & $0 \cdot 60 \mathrm{MPI} 1+0 \cdot 40($ for $\mathrm{MPR}<2 \cdot 65)$ & Radke et al (1986) & 0.75 & $1 \cdot 12$ \\
\hline MPR 1 & $1-\mathrm{MP} / \mathrm{P}$ & Radke et al (1982a) & $2 \cdot 50$ & 0.78 \\
\hline MPR 2 & 2-MP/P & Radke et al (1982a) & 0.67 & $1 \cdot 00$ \\
\hline MPR 3 & 3-MP/P & Radke et al (1982a) & $1 \cdot 00$ & $0 \cdot 90$ \\
\hline MPR 9 & 9-MP/P & Radke et al (1982a) & $0 \cdot 83$ & 0.53 \\
\hline
\end{tabular}

$\mathrm{Rc}=$ Calculated vitrinite reflectance. 


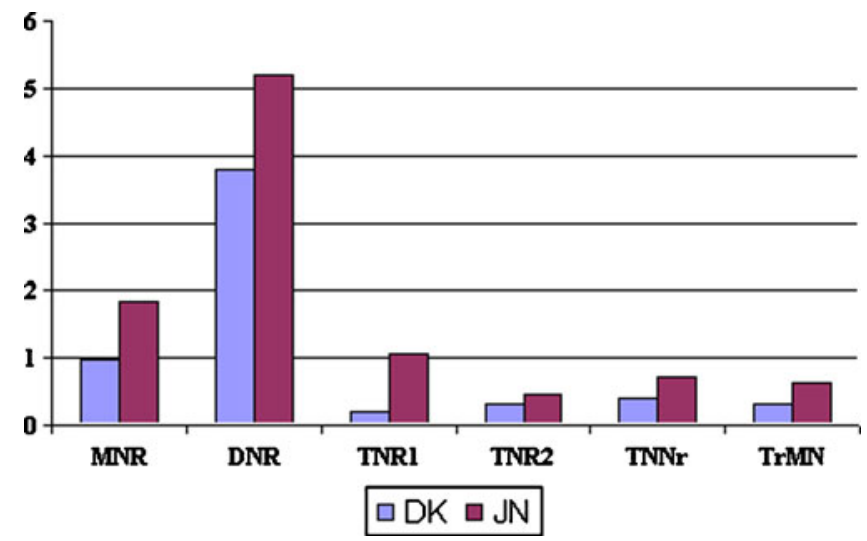

Figure 3. Comparison of methylnaphthalene ratios of DK and JN asphaltene pyrolysates.

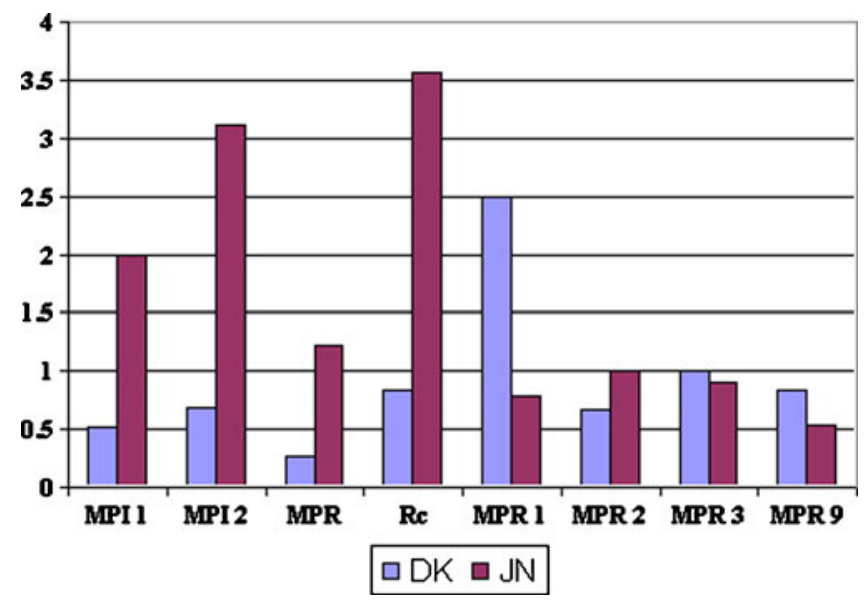

Figure 4. Comparison of methylphenanthrene ratios of DK and JN asphaltene pyrolysates.

and 9-methylphenanthrene. For both the asphaltenes, the concentration of 1-methylphenanthrene was higher than 9-methylphenanthrene. The 1-methylphenanthrene isomer is suggested to be produced from diterpenoid acids, specifically, dihydroabietic acid and podocarpic acid through reduction, followed by aromatization (Brassell 1985; Budzinski et al 1997), tentatively related 1-methylphenanthrene to a terrestrial origin and 9-methylphenanthrene to a marine origin. Both the asphaltenes thus appears to be of terrestrial origin. The methylphenanthrene ratio (MPR) for DK and $\mathrm{JN}$ is 0.27 and 1.23 , respectively. MPR $>1$ for JN reveals the predominance of more stable 2-methylphenanthrene over less stable 1-methylphenanthrene. The reverse is the case for DK. This indicates a higher level of thermal maturity of JN vs DK. MPI 1 is dependent on phenanthrene and methylphenanthrene homologues. With increasing maturity, $\alpha$-methylphenanthrenes are gradually converted to the more stable $\beta$-methylphenanthrenes. The MPI 1 and MPI 2 values for JN is much greater than that of DK. The MPI 3 values for DK and JN are 0.5 and 1.4. This indicates that DK asphaltenes are immature (MPI $3<0 \cdot 8$, respectively.
Radke et al (1987) and JN asphaltenes are exceptionally mature (MPI $3>1 \cdot 0$, Radke 1987 and Stojanovic et al 2001). This indicates that JN asphaltenes have reached much higher level of thermal maturity than DK asphaltenes.

\section{Conclusions}

Pyrolysis of the two asphaltenes produced aliphatic as well as aromatic compound classes to varying extents. Some of the aromatic compound classes, like alkylnaphthalenes and alkylphenanthrenes, which were previously been used to assess the maturity of crude oil, coal, etc. from their respective aromatic fractions can be utilized to assess the maturity of asphaltenes also. For both the asphaltenes, the concentration of 1-methylphenanthrene predominated over 9-methylphenanthrene revealing the terrestrial nature of organic matter in them. Alkylnaphthalenes and alkylphenanthrenes ratios revealed that JN asphaltene is more matured than DK asphaltene. The aromatic biomarkers like methylnaphthalenes and methylphenanthrenes produced from asphaltene pyrolysates can be used for maturity assessment for asphaltenes and the results can be combined with other maturity assessment techniques like, biomarker analysis of the saturated and aromatic fractions of crude oil to get a better understanding of their maturities as there exists striking physical and chemical similarities between oil forming kerogen and petroleum asphaltenes.

\section{Acknowledgements}

The authors are grateful to M/s Oil India Limited, Duliajan, Assam, India for giving permission to carry out their work at its R\&D laboratory. The authors also acknowledge Dr P G Rao, Director, NEIST, Jorhat, Assam, India for providing facilities and permission to publish these results.

\section{References}

Achari R G, Shaw G and Hollyhead R 1993 Chem. Geol. 12229

Alexander R, Kagi R I, Rowland S J, Sheppard P N and Chirila T V 1985 Geochim. et Cosmochim. Acta 49385

Alexander R, Bastow T P, Kagi R I and Singh R K 1992 J. Chem. Soc. Chem. Commun. 19061712

Arefyev O A, Makushin A and Petrov A A 1982 Int. Geol. Rev. 24 723

Asif M and Tahira F 2007 J. Res. Sci. 1879

Borrego A G, Blanco C and Püttmann W 1997 Org. Geochem. 26 219

Brassell S C 1985 Philos. Trans. R. Soc. A 31557

Brassel S C, Murchison D G, Mason R, Durand B, Englinton G, Comet P A, Curtis C D, Bada J and DeLeeuw J W 1985 Philos. Trans. R. Soc. A 31557

Budzinski H, Garrigues P, Connan J, Devillers J, Domine D, Radke M and Oudin J L 1995 Geochim. Cosmochim. Acta 592043

Budzinski H, Garrigues P, Bernard G, Bellocq J, Hinriches J and Rullkötter J 1997 Scientific Results 155555 
Bunger J W and Li N C 1984 Chemistry of asphaltenes (Washington DC: Am. Chem. Soc.)

Carman R M and Craig W 1971 Aust. J. Chem. 24361

Day W C and Erdman J G 1963 Science 141808

Fisher S J, Alexander R and Kagi R I 1996 Polycyclic aromatic compounds (UK: Gordon and Breach) p. 257

Gonzalez E B, Groenzin H, Galeana C L and Mullins O C 2001 Energy Fuels 15972

Greiner A, Spyckerelle C and Albrecht P 1976 Tetrahedron 32257

Heppenheimer H, Steffens K, Püttman W and Kalkreuth W 1992 Org. Geochem. 18273

Hussler G, Connan J and Albrecht P 1984 Novel families of tetraand hexacyclic hopanoids predominant in carbonate rocks and crude oils (Oxford: Pergamon Press) Vol. 6, p. 39

Karrer W (ed) 1976 Konstitution and vorkommen der organischen pfanzenstoffe (exclusive alkaloids) (Basel, $\mathrm{CH}$ : Birkhäuser Verlag) 2nd ed, Vol. 12

Kawanalca S, Leontaritis K J, Park S J and Mansoori G A 1989 Thermodynamic and colloidal models of asphaltene flocculation in oil field chemistry: Enhanced recovery and production stimulation (eds) J K Borchardt and T Fu Yen (Washington, DC: Am. Chem. Soc.)

Kruge M A 2000 International Journal of Coal Geology 4327

Larter S R and Douglas A G 1982 J. Anal. Appl. 41

Moschopedies S E, Parkash S and Speight J G 1978 Fuel 57431

Mullins O C and Sheu E Y 1998 Structures and dynamics of asphaltenes (New York: Plenum Pub. Co)

Murata S, Mori T, Murakami A, Normura M and Nakamura K 1995 Energy Fuels 9119

Nali M, Corana F and Montanari L 1995 Rapid Commun. Mass Spectrom. 7684

Neurock M and Klein M N 1995 Molecular reaction modeling of the reaction pathways and kinetics of heavy hydrocarbon systems, Symp. petroleum chemistry and processing presented before the Division of Petroleum Chemistry, Inc. 210th national meeting (Chicago, IL: American Chemical Society) p. 700

Neurock M, Libanti C, Nigam A and Klein M T 1990 in Proceedings of the American Institute of Chemical Engineers Meeting (San Diego, CA)
Pentegova V A, Dubovenko Z V, Vol'skii L N, Vasiluk S M, Chirkova M A and Shmidt E N 1968 Siberian Chem. J. 211

Püttmann W and Villar H 1987 Geochim. Cosmochim. Acta 51 3023

Radke M 1987 Advances in petroleum geochemistry (London: Academic press)

Radke M, Garrigues P, Parlanti E, Bellocq J, Willsch H and Ewald M 1987 Journal of Chromatography A 12217

Radke M and Willsch H 1994 Geochim. Cosmochim. Acta 23 5223

Radke M, Welte D H and Willsch H 1982a Geochim. Cosmochim. Acta 461

Radke M, Willsch H, Leythaeuser D and Teichmüller M 1982b Geochim. Cosmochim. Acta 461831

Radke M, Welte D H and Willsch H 1986 J. Org. Geochem. 1051

Rubinstein I and Strausz O P 1979 Geochim. et Cosmochim. Acta 431

Sheu E Y and Mullins O C 1995 Asphaltenes: Fundamentals and applications (New York: Plenum Pub. Co.)

Simoneit B R T, Grimalt J O, Wang T G, Cox R E, Hatcher P G and Nissenbaum A 1986 Org. Geochem. 10877

Speight J G and Moschopedis B C 1981 Chemistry of asphaltenes (eds) J W Bunger and N C Li, in Advances in Chemistry Series No. 195 (Washington DC: American Chemical Society) p. 115

Stojanovic K, Jovancicevic B, Pevneva G S, Golovko J A, Golovko A K and Pfendt P 2001 Org. Geochem. 32721

Strachan M G, Alexander R and Kagi R I 1988 Geochim. Cosmochim. Acta $\mathbf{5 2} 1255$

Streibl M and Herout V 1969 Organic Geochemistry, chapter Terpenoids-especially oxygenated mono-, sesqui-, di-, and triterpenes (eds) G Eglinton and M T J Murphy (Berlin: Springer) p. 401

Thomas B R 1970 Phytochemical phylogeny, chapter: modern and fossil plant resins (London: Academic Press) p. 59

van Aarssen B G K, Alexander R and Kagi R I 2000 Geochim. et Cosmochim. Acta 641417

Yasar M, Trauth D M and Klein M T 2001 Energy Fuels 15504

Zhang S, Huang H, Xiao Z and Liang D 2005 Org. Geochem. 36 1215 